\title{
POLYCYSTIC OVARIAN SYNDROME AND HYPERINSULINAEMIA
}

\author{
Fauzia Adil, Humera Ansar and Aftab A. Munir
}

\begin{abstract}
OBJECTIVE: To determine the occurrence of hyperinsulinaemia in women with polycystic ovarian syndrome (PCOS).

DESIGN: A descriptive study.

SETTING: Isra University Hospital, Hyderabad from January 2002 to December 2003.

METHODS: Total 64 subjects were recruited from gynaecological outpatients department, between the ages of $\mathbf{1 5}$ and $\mathbf{4 0}$ years with clinical diagnosis of polycystic ovarian syndrome, presenting with weight gain, oligomenorrhoea, secondary amenorrhoea, hirsuitism or infertility and either ultrasound evidence of PCOS or raised Leutinizing Hormone (LH)/ Follicular Stimulating Hormone (FSH) ratio. Patient's venous blood was checked for fasting serum insulin.

RESULTS: Out of total 64 women selected, 37(57.81\%) were between 21 - 30 years of age. Weight gain was the commonest presenting complain $(84.37 \%)$ followed by oligomenorrhoea (79.68\%). Infertility was found in 46 women $(\mathbf{7 1 . 8 7 \% )}$ and hyperandrogenism was observed in 43 women (62.49\%). Thirty-nine women (60.93\%) had ultrasound evidence of PCOS and $43(67.18 \%)$ had LH / FSH ratio greater than 2:1. Hyperinsulinaemia was seen in $27(42.19 \%)$ women.

CONCLUSION: In this study, 27 women (42.19\%) had hyperinsulinaemia which indicates significant insulin resistance. Thus, all the patients presenting with clinical or biochemical evidence of PCOS must undergo checking of fasting serum insulin levels.
\end{abstract}

KEY WORDS: Polycystic ovarian syndrome. Hyperinsulinaemia. Insulin resistance.

\section{INTRODUCTION}

Polycystic ovarian syndrome (PCOS) has a controversial definition. $1990 \mathrm{NIH}$ diagnostic criteria have used a working definition that a patient must have ovulatory dysfunction and evidence of hyperandrogenism clinically or by laboratory means, but no other cause of hyperandrogenism. ${ }^{1,2}$ It is also defined as a heterogenous disorder which may present at one end of the spectrum, with the single finding of polycystic ovarian morphology as detected by pelvic ultrasound. At the other end of the spectrum, symptoms such as obesity, hyperandrogenism, menstrual cycle disturbances and infertility may occur either singly or in combination., 2003 Rotterdam diagnostic criteria have included the presence of two out of three manifestations for the diagnosis of PCOS i.e. irregular or absent ovulation, clinical and / or biochemical hyperandrogenism and / or polycystic ovaries on ultrasound. ${ }^{5,6}$ Thus, it is chiefly a diagnosis of exclusion. ${ }^{7}$ Most reporters suggest that the condition affects between 5 and 10 percent of women of reproductive age. ${ }^{8}$ It is the most common endocrinological condition observed from premenstrual to perimenopausal age. Unfortunately, its exact etiology remains still uncertain ${ }^{3,9,10}$ and from time to time hypothalamus, pituitary, adrenals and ovaries have been held responsible to be the causal factor, alone or together. Lately, insulin resistance leading to hyperinsulinaemia ${ }^{11}$ and excessive leptin secretion have been associated with PCOS, but the role of leptin causing PCOS is inconclusive. ${ }^{12} \mathrm{~A}$ significant proportion of obese women with PCOS have greater insulin resistance than normal women. PCOS with hyperinsulinaemia is an established risk factor for non-insulin dependent diabetes, hypertension, dyslipidemia and cardiovascular disease, collectively known as metabolic syndrome or syndrome $X$. Thus, detection of insulin resistance in PCOS may assist in planning optimal treatments for anovulatory infertility and hyperandrogenaemia. ${ }^{13-15}$

Historically, the first report of a link between hyperandrogensim and metabolic defect was published in 1921, when Achard and Thiers described diabetes in bearded women. ${ }^{16}$ Later in 1935, Stein and Leventhal reported a series of seven women with bilateral polycystic ovaries and thickened ovarian cortex accompanied by amenorrhea, hirsuitism and infertility, but with no clear emphasis on the etiology of the disorder. ${ }^{17}$ It has become recognized increasingly that PCOS and insulin resistance are intimately related with respect to pathogenesis, endocrinal disturbances and molecular biology. ${ }^{3}$ The relative hyperinsulinaemia, which many feel is the key pathogenesis of the syndrome contributes to 
hyperandrogenism by direct stimulation of ovarian androgen production, decreasing sex hormone binding globulin and permits the survival of follicles by suppressing apoptosis. ${ }^{9}$ Hyperinsulinaemia generally suggests a lack of receptor sensitivity to insulin effects for unknown reasons. ${ }^{18}$ The question remains that what is the prevalence of hyperinsulinaemia in PCOS patients in our part of the world?. Therefore, this study explores this issue.

\section{PATIENTS AND METHODS}

This descriptive study included total 64 subjects, which were selected from the gynaecology outpatients department of Isra University Hospital, Hyderabad over a period of two years from January 2002 to December 2003 on the basis of following criteria.

\section{Inclusion criteria:}

Women between 15 - 40 years of age.

Any one of the following clinical presentation:

Secondary amenorrhoea or oligomenorrhoea with weight gain.

Secondary amenorrhoea or oligomenorrhoea with infertility.

Secondary amenorrhoea or oligomenorrhoea with hyperandrogenism (acne and / or hirsuitism).

Any one of the two evidences of PCOS:

a. Ultrasound of the pelvis showing polycystic ovaries (10 or more follicles of $10 \mathrm{~mm}$ or less in size).

b. LH/ FSH ratio greater than 2:1.

\section{Exclusion criteria:}

Diabetic patient.

Thyroid disorders.

Adrenal hyperplasia.

Hyperprolactinaemia.

Secondary amenorrhoea was defined as cessation of menstruation for six months in reproductive age group and was not due to pregnancy. Oligomenorrhoea means menses at intervals of more than 35 days. ${ }^{10}$ Weight gain was a subjective symptom of patients but it was determined by measuring basal metabolic index (BMI). BMI > 25 was considered as over weight while $>30$ was considered as obese as recommended by The U.S. preventive services task force (USPSTF) ${ }^{19}$ Infertility was described as inability of a couple to conceive within one year ${ }^{20}$ and hirsuitism was defined as a woman having increased or excessive body hair particularly on her face, breast or legs compared with the other women of her ethnic group. ${ }^{21}$ All these women underwent detailed history and thorough clinical examination including height in meters and weight in kilograms. They were advised for random blood sugar, serum prolactin and serum TSH to exclude other endocrine disorders. They also underwent serum $\mathrm{FSH}$ and $\mathrm{LH}$ and ultrasonography of the pelvis to fit into the selection criteria. Ultrasonography was performed to identify small multiple follicles with necklace appearance on the surface of the ovaries and to exclude other pelvic pathologies. LH/FSH ratio of greater than $2: 1^{10}$ was taken in the inclusion criteria. After fulfilling the selection criteria, all these women had their serum insulin levels checked by drawing 2cc of venous blood after a fasting of 12 hours. To standardize the test, it was carried out from single laboratory. Very high and low levels were rechecked. Normal range of values was taken as 3-17 micro U/ml.

\section{RESULTS}

Majority of women $37(57.81 \%)$ was between 21- 30 years of age (Table I). Weight gain was the commonest presenting complain found in 54 women $(84.37 \%)$ and after calculating the BMI, 29 women (45.31\%) were found to be over weight and 17 $(26.56 \%)$ were obese. Fifty-one women $(79.68 \%)$ gave history of oligomenorrhoea. Infertility was found in 46 women $(71.87 \%)$ while signs of hyperandrogenism including hirsuitism and acne were seen in $31(48.43 \%)$ and $9(14.06 \%)$ women respectively. Ultrasound evidence of PCOS was observed in $39(60.93 \%)$ women and LH/FSH ratio greater than 2:1 was seen in $43(67.18 \%)$ women (Table II). Fasting serum insulin levels were normal in 21 (32.18\%) women, while $43(67.18 \%)$ women had levels above 17 micro $\mathrm{U} / \mathrm{ml}$ indicating hyperinsulinaemia (Table III).

TABLE I: AGE DISTRIBUTION OF THE SUBJECTS $(n=64)$

\begin{tabular}{|c|c|c|}
\hline Age & $\begin{array}{c}\text { Number of } \\
\text { subjects }\end{array}$ & Percentage \\
\hline $15-20$ years & 18 & 28.12 \\
\hline $21-30$ years & 37 & 57.81 \\
\hline $31-40$ years & 09 & 14.07 \\
\hline
\end{tabular}

TABLE II:

DIAGNOSTIC CRITERIA OF WOMEN WITH PCOS $(n=64)$

\begin{tabular}{|l|c|c|}
\hline \multicolumn{1}{|c|}{ Criteria } & $\begin{array}{c}\text { Number of } \\
\text { patients }\end{array}$ & Percentage \\
\hline Oligomenorrhoea & 51 & $79.68 \%$ \\
\hline Secondary amenorrhea & 13 & $20.31 \%$ \\
\hline Weight gain & 54 & $84.37 \%$ \\
\hline - Over weight & 29 & $45.31 \%$ \\
\hline - Obese & 17 & $26.56 \%$ \\
\hline Infertility & 46 & $71.87 \%$ \\
\hline Hirsuitism & 31 & $48.43 \%$ \\
\hline Acne & 09 & $14.06 \%$ \\
\hline Ultrasound evidence & 39 & $60.93 \%$ \\
\hline LH / FSH ratio > 2:1 & 43 & $67.18 \%$ \\
\hline
\end{tabular}




\section{TABLE III: \\ SERUM INSULIN LEVELS OF SUBJECTS DIAGNOSED AS HAVING POLYCYSTIC OVARIAN SYNDROME $(n=64)$}

\begin{tabular}{|l|c|c|}
\hline \multicolumn{1}{|c|}{ Insulin level } & $\begin{array}{c}\text { Number of } \\
\text { patients }\end{array}$ & Percentage \\
\hline $3-10 \mathrm{micro} U / \mathrm{ml}$ & 21 & 32.81 \\
\hline$>10-14 \mathrm{micro} \mathrm{U/ml}$ & 09 & 14.06 \\
\hline$>14-17 \mathrm{micro} \mathrm{U/ml}$ & 07 & 10.93 \\
\hline$>17 \mathrm{micro} \mathrm{U} / \mathrm{ml}$ & 27 & 42.19 \\
\hline
\end{tabular}

\section{DISCUSSION}

PCOS is chiefly a metabolic syndrome which comes to the Gynaecologist. ${ }^{22}$ It is a subject of continuous studies concerning pathogenesis, diagnostic methods and therapeutic procedures. Now a days, most attention is focused on the role of insulin resistance and hyperinsulinaemia in development of the syndrome. ${ }^{23}$ However, one problem remains important and controversial that how many women having PCOS are affected by hyperinsulinaemia. The subjects selected in this study were between $15-40$ years of age as PCOS is mainly the problem of reproductive age group. $^{24}$ Most of the patients (57.81\%) were between $21-30$ years of age. Several studies have described that it may be peripubertal in onset and gets worse as the age advances. Although, it is not known at what age they first appear. ${ }^{3}$ However, Bridges et al (1993) performed 428 ovarian scans in girls aged between three and eighteen years and found polycystic ovaries in 101 (24\%). The polycystic ovaries were $6 \%$ in 6 years old girls rising to $18 \%$ in 10 years and $26 \%$ in those aged 15 years. The implication of this study may be that polycystic ovaries are present before puberty and are easier to detect in older girls as the ovaries increase in size. ${ }^{25}$ Barclay has mentioned that "in PCOS no constellation of findings or set criteria can exclusively be used for a clinical diagnosis or for inclusion in clinical research". ${ }^{6}$ Meanwhile, Khan MI has proposed that presence of menstrual irregularity is must for the diagnosis of PCOS ${ }^{24}$ Thus, considering these views as well as NIH 1999 and Rotterdam 2003 definitions of PCOS, the inclusion criteria were decided. All the patients selected in this study had menstrual disturbances followed by oligomenorrhoea (79.68\%) and secondary amenorrhoea (20.13\%). Amenorrhoea was also the presenting complain for all of the subjects in the series reported by Stein and Leventhal. However, in another study of 1741 women with PCOS, 30\% of patients had regular menses, whereas $66 \%$ had amenorrhea or oligomenorrhoea. ${ }^{1}$

In this study, 54 (84.37\%) women gave history of weight gain; $29(45.31 \%)$ over weight and 17
$(26.56 \%)$ obese on calculating their BMI. The prevalence of over weight and obesity varies between $40-70 \%$ in different studies..$^{3,14,26}$ Obesity is not a pre-requisite for PCOS but is likely to exacerbate some of its key biochemical features that are important in its pathophysiology. Fourty-six women $(71.87 \%)$ presented with infertility in this study. PCOS has been associated with anovulation in $75 \%$ of subjects described by Campbell S. ${ }^{10}$ It has also been stated that most women with PCOS ovulate intermittently and may take longer to conceive or may have fewer children than planned. Hyperandrogenism, which is an essential feature in the diagnosis of PCOS was observed in 40 women (62.49\%) in the form of hirsuitism and acne. Barclay has also stated hirsuitism as the best clinical marker of hyperandrogenism. ${ }^{6}$ In two large studies, the prevalence of hirsuitism in PCOS varied from $56 \%$ in normal weight women to $70 \%$ among obese women with PCOS. ${ }^{17}$ Ultrasound evidence of PCOS was found in 39 (60.93\%) women of our study population. It has been mentioned that diagnosis of PCOS does not always require the presence of polycystic ovaries. However, Khan MI reports that $80-100 \%$ of women with PCOS have polycystic ovaries. ${ }^{24} \mathrm{LH}$ hypersecretion is a wellestablished finding in women with PCOS. ${ }^{27} \mathrm{High} \mathrm{LH}$ is associated with androgen excess in such women. Raised LH / FSH ratio is found in $45.4 \%-94 \%$ of women with PCOS. ${ }^{28}$ While in this study, 43 (67.18\%) women had LH / FSH ratio greater than 2:1.

Insulin resistance is defined as a reduced glucose response to a given amount of insulin. ${ }^{2}$ It is known to occur naturally at puberty but to decline again during childhood, it may be that women with PCOS fail to resume levels of insulin sensitivity after puberty. ${ }^{8}$ Multiple etiological factors for this resistance have been suggested. It is also important to note that not all women with insulin resistance develop PCOS. In this study, 27 women (42.19\%) had serum insulin levels greater than 17 micro $\mathrm{U} / \mathrm{ml}$ indicating hyperinsulinaemia, while using the criteria described by Kidson $\mathrm{W}^{29}$ values between $10-14 \mathrm{~m} \mathrm{U} / \mathrm{ml}$ indicated mild insulin resistance ${ }^{30}$ and values above $14 \mathrm{mU} / \mathrm{ml}$ indicate moderate or severe insulin resistance. In various studies, insulin resistance has been found in $30-70 \%$ of patients with PCOS. ${ }^{7,10}$ Using the above values, 43 women (67.18\%) in this study had insulin levels greater than $10 \mathrm{mU} / \mathrm{ml}$ indicating mild to severe insulin resistance which is similar to the results found in other studies. But, as this was a single centre study with relatively smaller number of women, large multi-centre studies are recommended to establish more conclusive evidence. Moreover, comparison of various studies on PCOS becomes difficult as no fixed criteria have yet been met for establishing its diagnosis. 


\section{CONCLUSION}

Polycystic ovarian syndrome is the commonest endocrinal disorder found in the women attending gynaecological outpatients department. The fundamental defect of PCOS remains unknown and an area of ongoing study. Hyperinsulinaemia associated with PCOS was found $42.19 \%$ in this study, indicating that a significant number of women are having insulin resistance as a prime pathology in polycystic ovarian syndrome increasing the risk of obesity, cardiovascular diseases, diabetes and their complications in the future. But, unfortunately most women are not aware of these risks. Such studies can help us to identify these women at an early age, when preventive measures are most effective.

\section{REFERENCES}

1. Lewis V. PCOS: a diagnostic challenge. Obstet Gynecol Clin North Am 2001;28 (1):1-20.

2. Tsilchorozidou T, Overton C, Conway GS. The pathophysiology of polycystic ovarian syndrome. Clin Endocrinol 2004; 60(1):1- 17.

3. Baler AH. Secondary amenorrhea. In: Dewhurst's text book of obstetrics and gynecology for post graduates. Sixth edition. 1999. p.42-59.

4. Balen A. Endocrine methods of ovulation induction. Baillier's Clinical Obstetrics and Gynecology. 1998, p.521-539.

5. Cursons AJ, Stuckey BGA, Walsh JP, et al. Polycystic ovarian syndrome: marked differences between endocrinologists and gynaecologists in diagnosis and management. Clin Endocrinol 2005;62(3):289-295.

6. Barclay L. New guidelines for polycystic ovarian syndrome. Fertil Steril 2004; 81:19-25.

7. Legro RS and Azziz R. Androgen excess disorders. Danforth's obstetrics and gynecology. $9^{\text {th }}$ Edition: 2003, p. 663-672.

8. Hopkinson Z and Sattar N. A metabolic model for PCOS. Orgyn 2000; 3:52-56.

9. Baler A. Surgical management of polycystic ovarian syndrome: pros and cons. The Obstetrician and Gynecologist 2000; 2 (3):17-20.

10. Campbell $S$ and Monga A. Disorders of menstrual cycle. Gynaecology by Ten Teachers. $17^{\text {th }}$ edition. 2000, p. $47-63$.

11. Bloomgarden ZT. Highlights of the second world congress on the insulin resistance syndrome (Conference report). Medscape Diabetes and Endocrinology 2005;7:1. Available at: http:// www.medscape.com/viewarticle/505322.
12. Kalro BN, Loucks TL and Berga SL. Neuromodulation in PCOS. Obstet Gynecol Clin North Am 2001;28(1):35-62.

13. Kauffman RP, Baker VM, Marino PD, et al. Polycystic ovarian syndrome and insulin resistance in White and Mexican women: A comparison of two distinct populations. Am J Obstet Gynecol 2002; 187(5):1362 - 1369.

14. Norman RJ, Wu R and Stanziewicz MT. Polycystic ovary syndrome. Med J Aust 2004; 180(3):132-137.

15. Wild RA. Polycystic ovarian syndrome: a risk for coronary artery disease. Am J Obstet Gynecol 2002:186(1):35-43.

16. Fox R. PCOD and insulin resistance: pathophysiology and wider health issue. Prog Obstet Gynecol 1994;11:351-370.

17. Seli $E$ and Duleba AJ. Optimizing ovulation induction in women with PCOS. Curr Opin Obstet Gynecol 2002;14:245-253.

18. Zawar HA. PCOS hyperandrogenism and insulin resistance. Obstet Gynecol Clin North Am 2001;28(1):21-33.

19. USPSTF recommends obesity screening for all adults. Ann Intern Med 2003;139: 930-49.

20. Kandari NE and Cadieux M. Reproductive endocrinology and infertility. Current Obstetrics and Gynaecology. $9^{\text {th }}$ edition. 2003: $979-990$.

21. Jones DL. Human sexuality and psychosexual problems. Fundamentals of obstetrics and gynaecology. 1999: 235 - 240.

22. Hopkinson ZE, Sattar N and Fleming R. PCOS: the metabolic syndrome comes to gynecology. BMJ 1998; 317: 329-332.

23. Franks S, Gilling SC, Waston $\mathrm{H}$, et al. Insulin action in the normal and polycystic ovary. Endocrinol Metab Clin North Am1999;28:361- 78.

24. Khan MI and David MK. Polycystic ovarian syndrome. (2003) Available at: http:// www.emedicine.com.

25. Baler A. The polycystic ovarian syndrome. In: Gynecology by Robert W. Shaw. $3^{\text {rd }}$ edition, 2003; 259-270.

26. Polycystic ovary syndrome. Available at: http:// www.infertilityphysician.com/androgen/pcos.html.

27. Milsom SR, Sowter MC, Carter MA, et al. LH levels in women with polycystic ovarian syndrome:have modern assays made them irrelevant?. Br J Obstet Gynecol 2003; 110: 760764. 
28. Banaszewska B, Spaczynski RZ, Pawel PM. Incidence of elevated LH/FSH ratio in polycystic ovary syndrome women with normo and hyperinsulinaemia. Ann Academiae Medicae Biolostocensis 2003;48: 131-134.

29. Kidson W. Polycystic ovary syndrome: a new direction in treatment. Med J Aust 1998;169:537540.

30. Perloe M. Polycystic ovarian syndrome: treatment with insulin lowering medications. Available at: www.obgyn.net/pcos/articles/perloepcos.html.

\section{垱}

AUTHOR AFFILIATION:

Dr. Fauzia Adil (Corresponding Author)

Associate Professor

Department of Obstetrics and Gynecology

Isra University, P.O. Box \# 313, Hala Road,

Hyderabad - Sindh.

E-mail: adilfauzia@hotmail.com

Dr. Humera Ansar

Associate Professor

Department of Obstetrics and Gynecology

Isra University, Hala Road, Hyderabad - Sindh.

Prof. Aftab A. Munir

Department of Obstetrics and Gynecology

Isra University, Hala Road, Hyderabad - Sindh. 